\title{
AXONAL TRANSPORT OF LECTINS IN THE PERIPHERAL NERVOUS SYSTEM ${ }^{1}$
}

\author{
LAWRENCE F. BORGES ${ }^{*}{ }^{2}$ AND RICHARD L. SIDMAN $\ddagger$
}

Department of Neuroscience, Children's Hospital Medical Center, Boston, Massachusetts 02115, *Department of Neurosurgery, Massachusetts General Hospital, Boston, Massachusetts 02114, and $\ddagger$ Department of Neuropathology, Harvard Medical School, Boston, Massachusetts 02115

Received August 17, 1981; Revised November 19, 1981; Accepted December 30, 1981

\begin{abstract}
The binding and axonal transport of six lectins were studied in the peripheral nervous system of adult mice by an immunocytochemical method. After injection into muscle and subcutaneous sites, lectins known to bind preferentially $\mathrm{N}$-acetylglucosamine or mannose sugars were transported axonally to ventral horn and dorsal root ganglion neurons. Twelve to $96 \mathrm{hr}$ postinjection, these lectins were bound at the injection site to neuromuscular junctions, muscle spindles, and cutaneous nerves. Lectins known to bind preferentially $N$-acetylgalactosamine or galactose sugars, by contrast, were transported only to dorsal root ganglion neurons. Except for Sophora japonica agglutinin, these lectins were bound at the injection site only to cutaneous nerves. These differences in axonal transport were seen also when the lectins were applied directly to the proximal end of a transected mixed nerve.
\end{abstract}

The demonstration by Kristensson and Olsson (1971) that peripheral axons transport exogenous proteins retrogradely from terminal to soma initiated a new direction in neurobiological research that gained rapid momentum when LaVail and his co-workers (LaVail and LaVail, 1972; LaVail et al., 1973) showed that several axon pathways within the central nervous system also retrogradely transported horseradish peroxidase (HRP) and suggested that this could form the basis for a new technique to visualize patterns of neuronal connectivity (Kuypers et al., 1974; Nauta et al., 1974; LaVail, 1978).

As additional tracer molecules have come into use, evidence has accrued that axons are capable of selective transport. Nerve growth factor (NGF), crucial for the normal development of the peripheral sympathetic and sensory nervous systems (Levi-Montalcini and Angeletti, 1968), is transported retrogradely in sympathetic and sensory axons, but not in motor axons, after exogenous injection (Stöckel et al., 1975). Since the axonal uptake

\footnotetext{
' This study was supported by National Institutes of Health Grant NS-14768-04 and Contract RFP 690-33-77 from the Veterans Administration. Dr. Borges was a recipient of National Institutes of Health Neurosciences Research Training Grant NS-07170. We would like to thank Mr. Lawrence Appleman for typing the manuscript and $\mathrm{Mr}$. Wolfgang Busse for photographic assistance.

${ }^{2}$ To whom correspondence should be addressed at Department of Neuroscience, Enders 2, Children's Hospital Medical Center, 300 Longwood Avenue, Boston, MA 02115.
}

of labeled NGF is saturable and can be inhibited selectively by unlabeled NGF, specific binding to high affinity sites on the nerve terminal membrane is probably responsible for initiating the transport (Dumas et al., 1979). Retrograde axonal transport of other proteins, including tetanus and cholera toxins, wheat germ agglutinin, and antibodies to dopamine $\beta$-hydroxylase, is also probably initiated by a binding of the compound to specific high affinity sites nonuniformly distributed on the membranes of different classes of axon terminals (Fillenz et al., 1976; Ziegler et al., 1976; Stöckel et al., 1977; Dumas et al., 1979). However, of these agents, selective axonal transport is a known feature only for antibodies to dopamine $\beta$-hydroxylase, which are retrogradely transported selectively in adrenergic neurons (Fillenz et al., 1976).

Among these proteins, our attention became focused on wheat germ agglutinin (WGA), one of a series of plant lectins. Lectins are proteins capable of high affinity, noncovalent binding to specific saccharide components of glycoproteins and glycolipids on cell membranes (Brown, 1978). Further, lectin binding sites are distributed nonuniformly on the surfaces of individual neurons in culture (Pfenninger and Maylie-Pfenninger, 1979), among neuronal types in culture (Pfenninger and MayliePfenninger, 1978; Denis-Donini et al., 1978; Hatten and Sidman, 1977, 1978), and in histological sections (Colman and Taylor, 1974; Kelly et al., 1976; Zanetta et al., 1978; Hatten et al., 1979). The present study shows for the first time that several lectins are transported retrogradely in 
axons of the peripheral nervous system and that the differences in their distribution between motor and sensory neurons appear to correlate with their carbohydrate affinities (preliminary report, Borges and Sidman, 1981).

In previous studies of lectin retrograde transport, WGA was visualized via a radiolabel in autoradiograms (Schwab et al., 1978; Dumas et al., 1979; Steindler and Deniau, 1980) or as an HRP conjugate (Gonatas, 1979; Gonatas et al., 1979; Brushart and Mesulam, 1980; Staines et al., 1980; Harper et al., 1980). Either of these methods might have served our present purposes, but the autoradiographic technique is time consuming and cytologically imprecise, and lectin. HRP complexes may be endocytosed and transported in axons differently from free lectin (Silverstein et al., 1977). Therefore, we developed an immunocytochemical method for independently localizing any of several free, unlabeled lectins in histological sections. Preliminary reports of similar techniques for lectin tracing in the CNS have appeared by other investigators (Sherk and LeVay, 1979; Coulter et al., 1979, 1980).

\section{Materials and Methods}

Lectins purified by affinity chromatography (wheat germ agglutinin (WGA), concanavalin A (Con A), soybean agglutinin (SBA), Dolichos bifloris agglutinin (DBA), Saphora japonica agglutinin (SJA), and Bandieraea simplicifolia lectin I (BSL)), and antilectin antisera produced in rabbits were purchased from Vector Laboratories (Burlingame, CA). Fluorescein- (WGA and Con A) and rhodamine- (Con A, SBA, and DBA) conjugated lectins also were purchased from Vector Laboratories. Additional immunochemicals were obtained from Miles Laboratories (Elkhart, IN). Hapten sugars (Table I) were purchased from Sigma Chemical Co. (St. Louis, MO). Chitin hydrolysates prepared according to the method of Rupley (1964) were a generous gift of Dr. William Weimar (Department of Neuroscience, Children's Hospital Medical Center, Boston, MA). The remainder of the chemicals were analytical grade.

Fifty adult C57BL/6J mice were anesthetized with Avertin $10.1 \mathrm{ml} / 5 \mathrm{gm} ; 0.5 \mathrm{gm}$ of tribromoethanol dissolved with $0.25 \mathrm{gm}$ of 2 -methyl-2-butanol in $39.5 \mathrm{ml}$ of distilled water) and received 5- $\mu$ l injections of 0.5 to $2.0 \%$ lectin in $0.1 \mathrm{M}$ phosphate buffer $(\mathrm{pH} 7.4)$ into flexor forelimb muscle and skin. Each mouse received a single unilateral lectin injection. After survival periods of 12 to
$96 \mathrm{hr}$, the mice were reanesthetized and perfused through the left ventricle of the heart with a physiological saline rinse at room temperature followed by a fixative at $4^{\circ} \mathrm{C}$. Either of two fixatives were used: $2 \%$ paraformaldehyde in $0.1 \mathrm{M}$ phosphate buffer ( $\mathrm{pH} 7.4$ ) or the paraformaldehyde/periodate/lysine fixative of McLean and Nakane (1974) except for the substitution of $50 \%$ ethanol in place of paraformaldehyde. Following a 15-min perfusion with fixative, the cervical spinal cord and its attached dorsal root ganglia were removed and postfixed in the respective fixalive for an additional $1.5 \mathrm{hr}$ at $4^{\circ} \mathrm{C}$. In some animals, the lectin injection site also was removed and processed. Thereafter, the tissue was dehydrated overnight at $4^{\circ} \mathrm{C}$ in several changes of methanol:ethylene glycol monomethyl ether (1:1) containing $1 \%$ distilled water and then infiltrated with several changes of polyester wax at $37^{\circ} \mathrm{C}$ for 12 to $24 \mathrm{hr}$ before embedding in polyester wax (Sidman et al., 1961). The polyester wax was prepared by melting $90 \mathrm{gm}$ of polyethylene glycol distearate 400 (Ruger, Irvington, NJ) and $10 \mathrm{gm}$ of cetyl alcohol (Fisher, Pittsburgh, PA) at $57^{\circ} \mathrm{C}$. When fully melted, these liquids were mixed vigorously at $57^{\circ} \mathrm{C}$ for $30 \mathrm{~min}$ and cooled to $37^{\circ} \mathrm{C}$. Distilled water was added to the wax to give a $1 \%$ final concentration (Feder, 1976). Sections cut at $20 \mu \mathrm{m}$ were floated onto albuminized slides (Pappas, 1971) and air-dried at room temperature overnight. The sections were dewaxed in three changes of acetone $(100 \%, 100 \%$ and $90 \%$ in distilled water), dried, and then rehydrated in Dulbecco's phosphate-buffered saline (Dulbecco and Vogt, 1954) for immunocytochemical processing according to the unlabeled antibody method of Sternberger et al. (1970).

The immunocytochemical reaction was performed at room temperature in Dulbecco's phosphate-buffered saline ( $\mathrm{pH} \mathrm{7.4)} \mathrm{containing} 1 \%$ normal goat serum. All of the incubations and washes contained $0.025 \%$ Triton X-100 except that the primary antibody incubation contained $0.4 \%$ Triton X-100 and the detergent was omitted from the peroxidase-antiperoxidase (PAP) incubation. Nonspecific staining was reduced by an initial 30 -min incubation in 5\% normal goat serum. The sections then were incubated for $90 \mathrm{~min}$ with the appropriate rabbit antilectin antibody $(1 / 200$ to $1 / 400)$. Following three 10 -min washes, the sections were incubated with goat anti-rabbit IgG $(1 / 20)$ for $30 \mathrm{~min}$ and washed again. Thereafter, they were incubated with a rabbit PAP complex $(1 / 40)$ for $30 \mathrm{~min}$. Following additional washes, the peroxidase was visual-

TABLE I

Correlation of lectin-carbohydrate affinity with the pattern of retrograde axonal transport

'The most lectin transported is shown by ++++ , while 0 indicates no lectin transport.

\begin{tabular}{|c|c|c|c|c|c|}
\hline \multirow[b]{2}{*}{ Lectin } & \multirow[b]{2}{*}{$M_{\mathrm{r}}$} & \multirow{2}{*}{$\begin{array}{l}\text { Carbohydrate } \\
\text { Binding } \\
\text { Specificity }\end{array}$} & \multicolumn{3}{|c|}{ Retrograde Axonal Transport } \\
\hline & & & $\begin{array}{l}\text { Ventral } \\
\text { Horn } \\
\text { Cells } \\
\end{array}$ & $\begin{array}{c}\text { Large } \\
\text { DRG }^{a} \\
\text { Neurons }\end{array}$ & $\begin{array}{c}\text { Small } \\
\text { DRG } \\
\text { Neurons }\end{array}$ \\
\hline Concanavalin A & $104,000^{b}$ & $\alpha$-D-Mannosyl & +++ & +++ & ++ \\
\hline Soybean agglutinin & 120,000 & $\mathrm{~N}$-Acetylgalactosaminyl & 0 & + & +++ \\
\hline Dolichos bifloris agglutinin & 113,000 & $N$-Acetylgalactosaminyl & 0 & + & ++ \\
\hline
\end{tabular}

" DRR, dorsal root ganglion.

${ }^{b} \mathrm{pH} 7$. 
ized with $3,3^{\prime}$-diaminobenzidine tetrahydrochloride (0.4\%; Sigma, St. Louis, MO) and hydrogen peroxide $(0.01 \%)$ in $0.1 \mathrm{~m}$ Tris-HCl $(\mathrm{pH} 7.6)$ for $8 \mathrm{~min}$. Sections were postfixed for $5 \mathrm{sec}$ in $0.5 \%$ osmium tetroxide in distilled water before being dehydrated, cleared, and coverslipped. The cervical spinal cord and dorsal root ganglia contralateral to the lectin injection site, the lumbar spinal cord in all lectin-injected mice, and sections of cord and ganglia from uninjected mice were processed simultaneously as controls.

In several mice, the right brachial plexus was exposed posteriorly and transected along its lateral aspect. A polyethylene cap containing lectin was placed over the proximal segments. After survival periods of 24 to $96 \mathrm{hr}$, the animals were processed as described above.

Localization of lectin binding in muscle and skin was assessed further in four mice with lectins coupled with fluorescent markers. Flexor forelimb muscle and skin were removed en bloc from anesthetized C57BL/6J adult mice and were frozen, unfixed, on a microtome chuck with powdered dry ice. Sections were cut $10 \mu \mathrm{m}$ thick in a cryostat and thawed directly onto clean glass slides. After drying for $1 \mathrm{hr}$ at room temperature, these sections were rehydrated in $\mathrm{Ca}^{2+}, \mathrm{Mg}^{2+}$-free phosphate-buffered saline $(\mathrm{pH} 7.4)$ and incubated with fluorescein- (WGA and Con A) or rhodamine- (Con A, SBA, and DBA) conjugated lectins according to the protocol of Hatten et al. (1979). After washing and coverslipping with glycerol:phosphate-buffered saline (9:1), these sections were examine with a Zeiss epifluorescence microscope. Control sections were incubated according to the same protocol with fluorescein- and rhodamine-conjugated bovine serum albumin that contained unbound fluorochrome (Landel, 1976).

Additional controls performed for all groups of animals included preincubating the lectin with its hapten sugar (Table I) prior to its injection or application to tissue sections. The lectins were preincubated with 0.2 to 1.0 M soluble hapten sugars in phosphate buffer $(\mathrm{pH} 7.4)$ for $1 \mathrm{hr}$ at $37^{\circ} \mathrm{C}$. In addition, WGA was preincubated with 0.1 to $0.4 \mathrm{~m}$ soluble chitin hydrolysates.

\section{Results}

General. All animals tolerated the lectin injections without evidence of systemic toxicity. WGA produced local inflammation at the site of injection in all concentrations studied. This inflammation, as assessed qualitatively, was diminished when WGA was preincubated with $\mathrm{N}$-acetylglucosamine or chitin hydrolysates prior to injection.

Two fixatives were used in a search for a compromise between good morphological preservation and optimal immunocytochemical lectin staining. Superior morphological preservation was achieved with paraformaldehyde, but significantly more lectin could be identified immunocytochemically in tissue fixed with ethanol/periodate/lysine.

Lectin was represented by dark brown-black granules in the cytoplasm of neuronal somas and dendrites, while the nuclei remained unstained. All lectins studied exhibited similar cytoplasmic localization at the light microscope level. Survival periods of $12 \mathrm{hr}$ favored axonal staining of motoneurons, while more dendrites were labeled with 48-hr survival periods. Axons were only sparsely labeled within dorsal root ganglia and dorsal roots in most animals, but in some animals, afferent projections into the dorsal horn were labeled.

The contralateral side of the cervical cord, contralateral cervical dorsal root ganglia, and lumbar cord from lectin-injected animals, as well as the cervical cord and ganglia from non-lectin-injected animals, uniformly failed to demonstrate the lectin-specific granular staining. The only exception was that lectin-specific granular staining was found within the intermediate and ventral spinal cord grey matter on the contralateral side of several WGA-injected animals (Fig. 1A). This was thought to represent trans-synaptic transport of the WGA. Nonspecific staining was noted when concentrations of primary antisera greater than 1/100 were used. 'l'his nonspecific staining was easily recognized, however, appearing as a diffuse brown staining of the nucleus. The antisera were specific for their respective lectins and failed to cross-react with other lectins.

Axonal transport. Lectins injected into forelimb muscle and skin were found in spinal cord ventral horn cells and/or dorsal root ganglion neuron somas following a 12 hr survival period. Lectin accumulated progressively following longer survival periods but began to decrease by 72 to $96 \mathrm{hr}$ after injection. If the ipsilateral brachial plexus was ligated prior to injection, no intraneuronal lectin was observed.

WGA and Con A were found within ventral horn motoneurons and dorsal root ganglion neurons of various sizes (Figs. 1 and 2). Consistently fewer neurons were labeled in the Con A-injected animals (Fig. 2) compared to those receiving WGA (Fig. 1). The other lectins studied (SBA, DBA, SJA, and BSL) were axonally transported only to neurons of the dorsal root ganglia ipsilateral to the injection site and were never observed within ventral horn cells (Fig. 3). Within the dorsal root ganglia, these lectins localized predominantly to the smaller neurons, whereas WGA and Con A labeled both large and small neurons. This predilection for small neurons was demonstrated most dramatically by SBA and least clearly by SJA. These differences in axonal transport were maintained even when the lectins were applied to the ends of the proximal segments of the transected brachial plexus.

Lectin localization at the injection site. At the injection sites, WGA and Con A delineated the subneural apparatus of neuromuscular junctions, portions of muscle spindles, and cutaneous nerves. SBA, DBA, and BSL delineated only the cutaneous nerves and were never found localized to neuromuscular junctions or muscle spindles. SJA, by contrast with the other three $N$-acetylgalactosamine- and galactose-binding lectins, frequently labeled neuromuscular junctions as well as cutaneous nerves (Fig. 4).

Similar patterns of localized were observed when fluorescein- (WGA and Con A) or rhodamine- (Con A, SBA, and DBA) tagged lectins were incubated with sections of unfixed skin and muscle. All of the lectins labeled cutaneous nerves, whereas only WGA, Con A, and SJA labeled neuromuscular junctions and only WGA and Con A labeled axons of muscle spindles. Tissue sections in- 

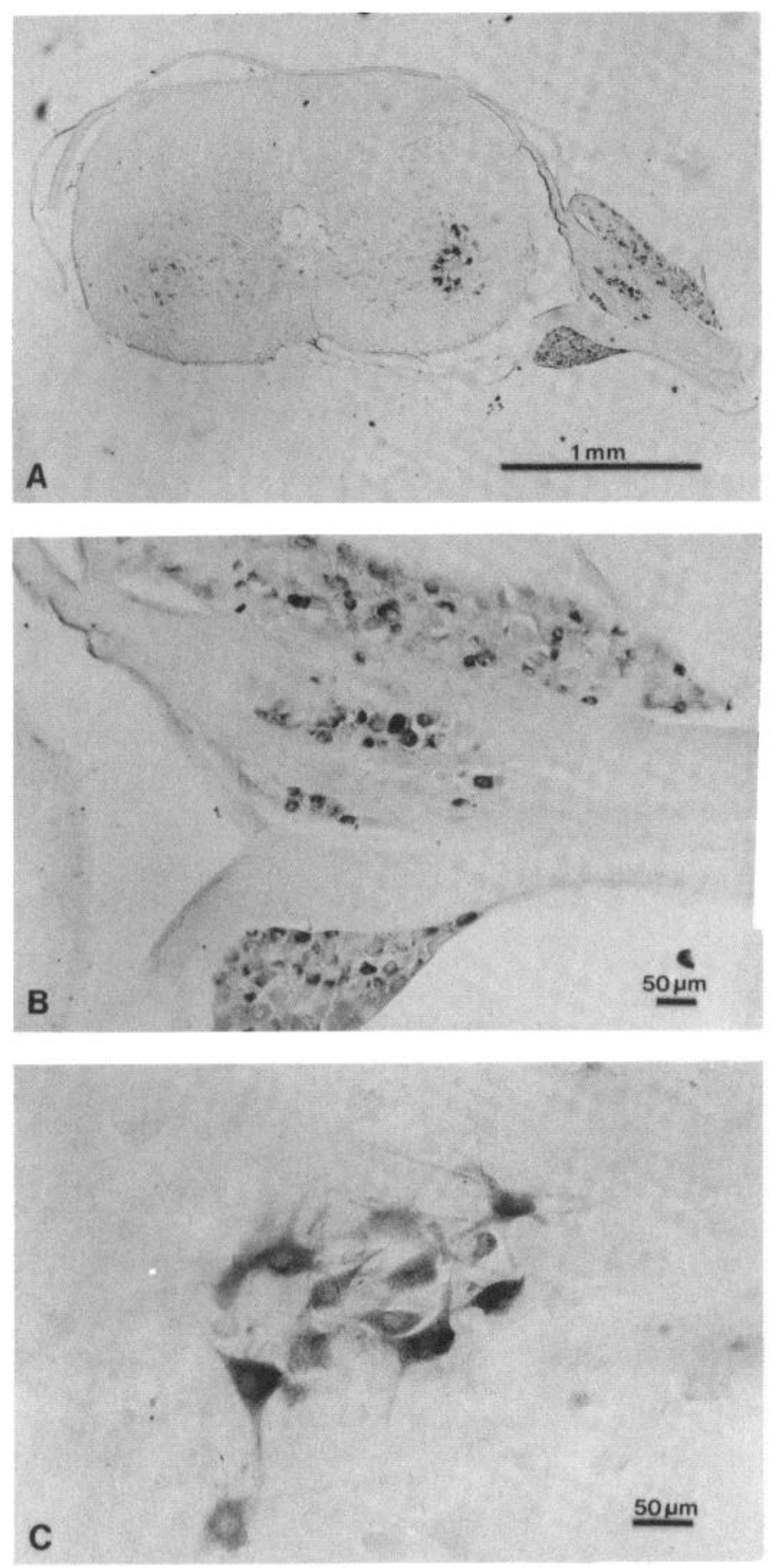

Figure 1. Neurons containing axonally transported WGA. A, WGA was injected into the flexor forelimb on the side of the attached dorsal root ganglion. Some labeled ventral horn cells are seen contralateral to the injection and probably represent the trans-synaptic transfer of WGA. B, WGA is present in dorsal root ganglion neurons of various sizes. $C$, Ventral horn motoneurons are well filled after this $48-\mathrm{hr}$ survival period.

cubated with fluorescein- and rhodamine-conjugated bovine serum albumin were not specifically labeled.

Hapten effects on lectin transport and binding. Preincubating the lectins with their specific hapten sugars failed to inhibit the axonal transport and binding of the lectins when the preincubated mixture was subsequently injected into skin and muscle. On the contrary, injecting this preincubated mixture significantly increased the amount of transport lectin, while the previously described qualitative pattern of axonal transport specificity was maintained. This phenomenon was most marked when WGA was preincubated with chitin hydrolysate and was noted for all concentrations of hapten sugars and chitin hydrolysate.

These in vivo observations contrasted with the results obtained directly on tissue sections. Preincubation of the fluorescently tagged lectins with their hapten sugars or chitin hydrolysate (WGA) significantly inhibited the specific binding to neuromuscular junctions, muscle spindle axons, and cutaneous axons as described for sections of CNS tissue by Hatten et al. (1979).

\section{Discussion}

This study confirms the preliminary reports of Sherk and LeVay (1979) and Coulter et al. $(1979,1980)$ by demonstrating that unlabeled lectins can be transported axonally. In addition, it supports the suggestion of Coulter et al. (1979) that WGA, or at least its antigenic component, can be transported trans-synaptically. However, the uptake and transport of particular lectins differentially among peripheral motor and sensory axons has not been reported previously. This novel finding merits extension to the CNS as a possible differential neuroanatomical tracing method.

While lectins are complex macromolecules, the property that correlated most closely with their observed transport specificity was their sugar binding affinity (Table I). Thus, lectins known to bind preferentially $N$ acetylglucosamine or mannose sugars were transported in motor and sensory neurons, while those known to bind $\mathrm{N}$-acetylgalactosamine or D-galactose were transported only in sensory neurons. These results imply that motor and sensory neurons may differ in their surface glycoconjugates.Confirmation of this hypothesis must await the development of techniques for identifying specific glycoconjugates on neuronal membranes. Since three lectins

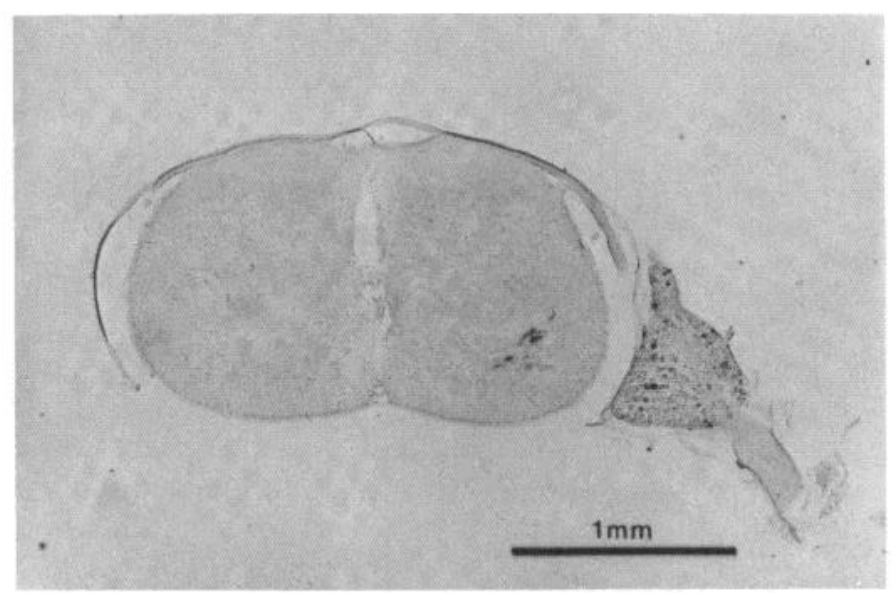

Figure 2. Neurons containing axonally transported Con A. The pattern of neuronal labeling is similar to that seen with WGA in Figure 1, although Con A consistently labels fewer neurons than WGA. 


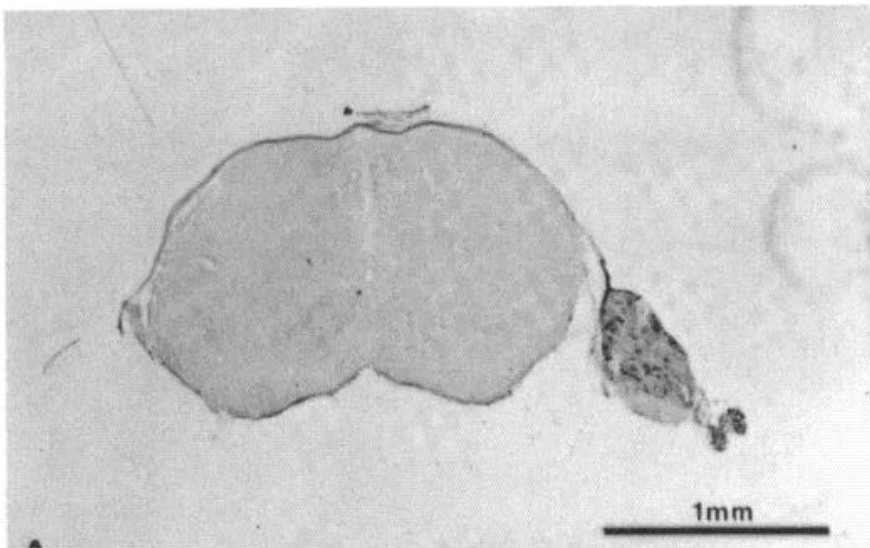

A
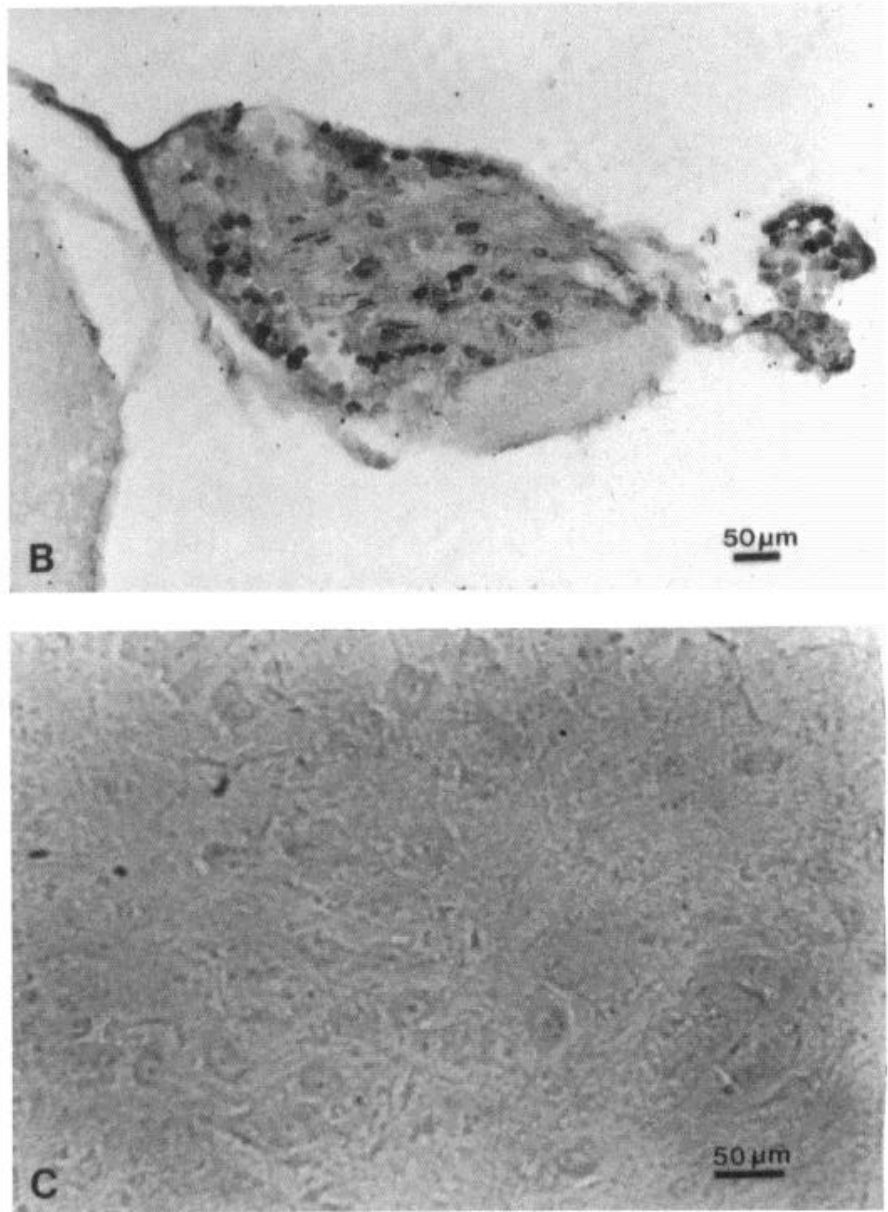

Figure 3. Neurons containing axonally transported SBA. $A$, At low magnification, only neurons within the dorsal root ganglion appear labeled. This is confirmed by examining the ventral horn motoneurons at high magnification $(C)$ where no granular cytoplasmic labeling can be found. Within the dorsal root ganglion $(B)$, the lectin is found primarily within smaller neurons. These photomicrographs are also representative of the axonal transport of DBA, SJA, and BSL (48-hr postinjection survival).

(SBA, DBA, and SJA) with similar sugar binding affinity also were transported to slightly different populations of dorsal root ganglion neurons, additional determinants, such as steric configuration, may be important in the differential axonal uptake and transport of macromolecules.

This study also demonstrated that the specificity of lectin transport was maintained when the lectins were applied to the proximal end of a severed peripheral nerve. This observation suggests that the mechanism of specific lectin transport does not reside solely at the axon terminal but is present throughout the axon. In the absence of detailed information about the rate and mechanism of membrane resealing of severed axons, we must consider that maintenance of selective lectin transport could reflect either a differential transport system for different macromolecules or distribution of selective binding affinities along the entire surface area of the axon. Neurons maintained in tissue culture have lectin receptors over their entire surface, although the receptors are concentrated at the axon terminals (Pfenninger and MayliePfenninger, 1979). The present study suggests that these surface receptors can be important in selecting exogenous macromolecules for retrograde axoplasmic transport.

Although the specificity of lectin binding and transport
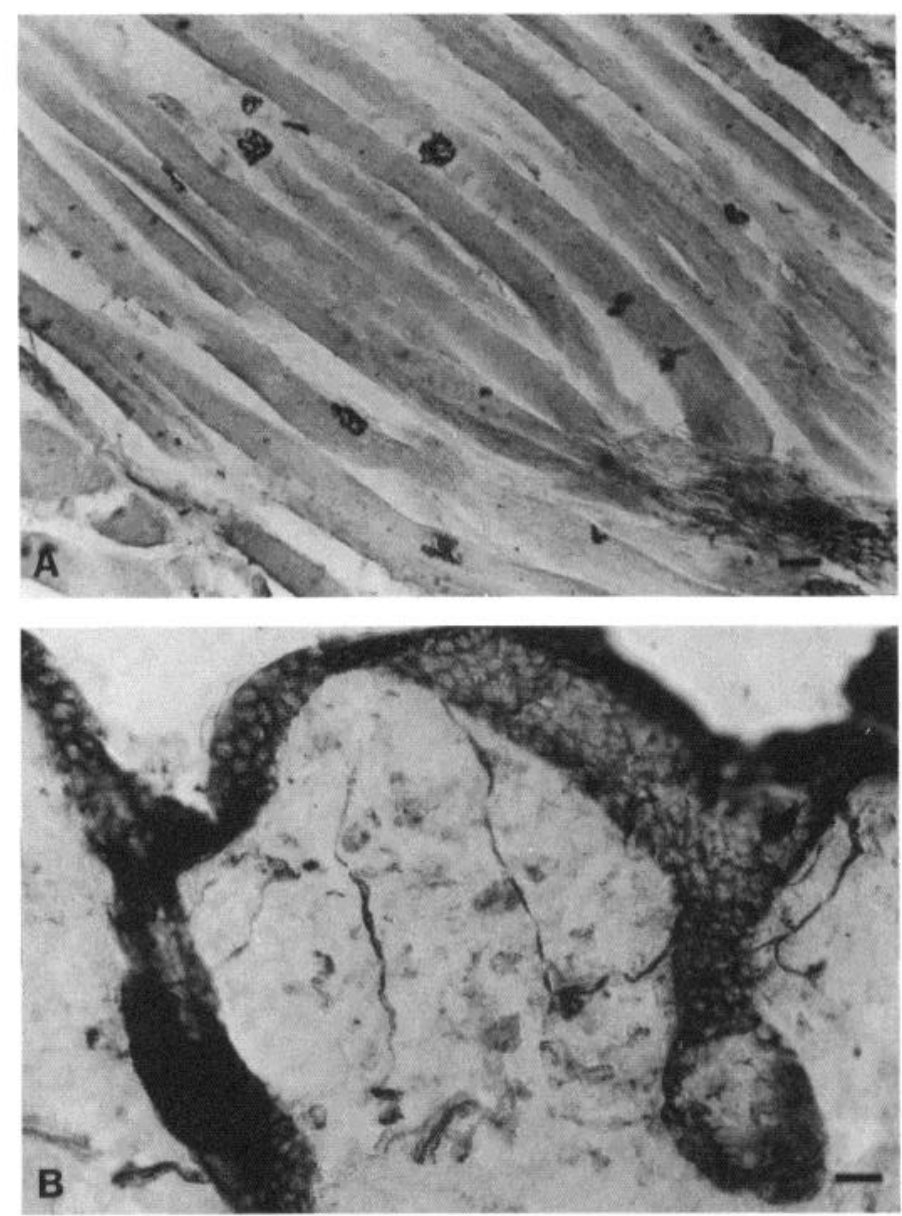

Figure 4. Pattern of lectin binding at the injection site. $A$, WGA injected into these flexor forelimb muscles $48 \mathrm{hr}$ prior to sacrifice is specifically bound to the neuromuscular junctions. Similar binding is seen with Con A and SJA. B, SJA injected into the flexor forelimb skin $48 \mathrm{hr}$ prior to sacrifice is specifically bound to the cutaneous nerves as well as residing between cells of the dermis. Similar binding is seen with all of the lectins studied. Bars, $50 \mu \mathrm{m}$. 
is probably secondary to specific lectin-carbohydrate binding at the axon membrane, we were unable to inhibit the binding and transport in vivo with hapten sugars. These same sugars did inhibit lectin binding in vitro on histological sections, a result demonstrating that the hapten sugars were active. Since neurons in vivo are capable of specific and nonspecific endocytosis (Gonatas, 1979), they may have taken up lectin.sugar complexes by nonspecific endocytosis and then axonally transported them. However, this mechanism would seem insufficient to explain the observed increase in axonally transported lectin plus sugar, compared to lectin alone. Lectin -sugar complexes would be expected to diffuse farther from the injection site than lectin alone and might result in more neurons or more terminal branches of a given neuron becoming labeled. Also, the sugar itself may have enhanced axonal uptake of the lectin -sugar complex (Barondes, 1968; Loopuijt et al., 1981), possibly by binding to an endogenous lectin or other selective component within the axonal membrane.

The immunocytochemical method of localizing bound and transported lectins provided an effective visualization technique that compared favorably in sensitivity with most HRP methods (L. F. Borges and R. L. Sidman, unpublished observations). It allowed us to recognize the differential distribution of lectins between motor and sensory neurons that might not have been observed in studies with lectin-HRP conjugates, especially with preparations containing free HRP, since the latter is well transported in peripheral axons generally. The immunocytochemical method holds further promise of being able to distinguish between multiple simultaneous lectin tracers, since several of the antibodies used for this study were immunologically noncross-reacting.

\section{References}

Barondes, S. H. (1968) Incorporation of radioactive glucosamine into macromolecules at nerve endings. J. Neurochem. 15: $699-706$.

Borges, L. F., and R. L. Sidman (1981) Differential uptake and transport of lectins by sensory and motor axons. Anat. Rec. 199: $32 \mathrm{~A}$.

Brown, J. C. (1978) Lectins. Int. Rev. Cytol. 52: 277-349.

Brushart, T. M., and M. M. Mesulam (1980) Transganglionic demonstration of central sensory projections from skin and muscle with HRP-lectin conjugates. Neurosci. Lett. 17: 1-6.

Cotman, C. W., and D. Taylor (1974) Localization and characterization of concanavalin A receptors in the synaptic cleft. $\mathrm{J}$. Cell Biol. 62: 236-242.

Coulter, J. D., M. C. Sullivan, and M. A. Ruda (1979) Lectins as markers for studies of neuronal connectivity. Soc. Neurosci. Abstr. 5: 339.

Coulter, J. D., M. A. Ruda, and R. M. Bowker (1980) Anterograde and retrograde axonal transport of lectins in the central nervous system. Anat. Rec. 196: 36A.

Denis-Donini, S., M. Estenoz, and G. Augusti-Tocco (1978) Cell surface modifications in neuronal maturation. Cell Differ. 7 : 193-201.

Dulbecco, R., and M. Vogt (1954) Plaque formation and isolation of pure lines with poliomyelitis virus. J. Exp. Med. 99: 167-182.

Dumas, M., M. E. Schwab, and H. Thoenen (1979) Retrograde axonal transport of specific macromolecules as a tool for characterizing nerve terminal membranes. J. Neurobiol. 10: 179-197.
Feder, N. (1976) Solitary cells and enzyme exchange in tetraparental mice. Nature 263: 67-69.

Fillenz, M., C. Gagnon, K. Stöckel, and H. Thoenen (1976) Selective uptake and retrograde axonal transport of dopamine- $\beta$-hydroxylase antibodies in peripheral adrenergic neurons. Brain Res. 114: 293-303.

Gonatas, N. K. (1979) Immunochemistry and receptors: Studies on the redistribution and absorptive endocytosis of antiimmunoglobulin antibodies, cholera toxin, and lectins. In Prog. ress in Neuropathology, H. M. Zimmerman, ed., pp. 51-60, Raven Press, New York.

Gonatas, N. K., C. Harper, T. Mizutani, and J. O. Gonatas (1979) Superior sensitivity of conjugates of horseradish peroxidase with wheat germ agglutinin for studies of retrograde axonal transport. J. Histochem. Cytochem. 27: 728-734.

Harper, C. G., J. O. Gonatas, A. Steiber, and N. K. Gonatas (1980) In vivo uptake of wheat germ agglutinin-horseradish peroxidase conjugates into neuronal GERL and lysosomes. Brain Res. 188: 465-472

Hatten, M. E., and R. L. Sidman (1977) Plant lectins detect age and region specific differences in cell surface carbohydrates and cell reassociation behavior of embryonic mouse cerebellar cells. J. Supramol. Struct. 7: 267-275.

Hatten, M. E., and R. L. Sidman (1978) Cell reassociation behavior and lectin-induced agglutination of embryonic mouse cells from different brain regions. Exp. Cell Res. 113: 111-125.

Hatten, M. E., M. Schachner, and R. L. Sidman (1979) Histochemical characterization of lectin binding in mouse cerebellum. Neuroscience 4: 921-935.

Kelly, P., C. W. Cotman, C. Gentry, and G. L. Nicholson (1976) Distribution and mobility of lectin receptors on synaptic membranes of identified neurons in the central nervous system. J. Cell Biol. 71: 487-496.

Kristensson, K., and Y. Olsson (1971) Retrograde axonal transport of protein. Brain Res. 29: 363-365.

Kuypers, H. G. J. M., J. Kievit, and A. C. Groen-Klevant (1974) Retrograde transport of horseradish peroxidase in the rat's forebrain. Brain Res. 67: 211-218.

Landel, A. M. (1976) Stability studies on fluorescein isothiocyanate-bovine serum albumin conjugate. Anal. Biochem. 73: 280-289.

LaVail, J. H. (1978) A review of the retrograde transport technique. In Neuroanatomical Research Techniques, R. T. Robertson, ed., pp. 356-384, Academic Press, New York.

LaVail, J. H., and M. M. LaVail (1972) Retrograde axonal transport in the central nervous system. Science 176 : 14161417.

LaVail, J. H., K. R. Winston, and A. Tish (1973) A method based on retrograde intraaxonal transport of protein for identification of cell bodies or origin of axons terminating within the CNS. Brain Res. 58: 470-477.

Levi-Montalcini, R., and P. U. Angeletti (1968) Nerve growth factor. Physiol. Rev. 48: 534-569.

Loopuijt, L. D., G. J. M. Hooghwinkel, and J. Voogd (1981) Retrograde transport of radioactivity along axons of ascending cerebellar pathways after injection of $n-\left[{ }^{3} \mathrm{H}\right]$-acetyl-Dmannosamine into the mesencephalon of the rat. Brain Res. 208: 1-17.

McLean, I. W., and P. K. Nakane (1974) Periodate-lysine-paraformaldehyde fixative. A new fixative for immunoelectron microscopy. J. Histochem. Cytochem. 22: 1077-1083.

Nauta, H. J. W., M. B. Pritz, and R. J. Lasek (1974) Afferents to the cat caudoputamen studied with horseradish peroxidase. An evaluation of a retrograde neuroanatomical research method. Brain Res. 67: 219-238.

Pappas, P. W. (1971) The use of a chrome alum-gelatin (subbing) solution as a general adhesive for paraffin sections. Stain Technol. 46: 121-124. 
Pfenninger, K. H., and M. -F. Maylie-Pfenninger (1978) Characterization, distribution and appearance of surface carbohydrates on growing neurites. In Neuronal Information Transfer, A. Karlin, H. Vogel, and V. M. Tennyson, eds., pp. 373-386, Academic Press, New York.

Pfenninger, K. H., and M. -F. Maylie-Pfenninger (1979) Surface glycoconjugates in the differentiating neuron. In Complex Carbohydrates of Nervous Tissue, R. U. Margolis and R. K. Margolis, eds., pp. 185-191, Plenum Press, New York.

Rupley, J. A. (1964) The hydrolysis of chitin by hydrochloric acid and the preparation of low-molecular weight substrate for lysozyme. Biochim. Biophys. Acta 83: 245-255.

Schwab, M. E., F. J. Agid, and Y. Agid (1978) Labelled wheat germ agglutinin (WGA) as a new, highly sensitive retrograde tracer in the rat brain hippocampal system. Brain Res. 152: 145-150.

Sherk, H., and S. LeVay (1979) Axonal transport of lectins from cat visual cortex demonstrated with an immuno-peroxidase method. Soc. Neurosci. Abstr. 5: 808.

Sidman, R. L., P. A. Mottla, and N. Feder (1961) Improved polyester wax embedding for histology. Stain Technol. 36: 279-284.

Silverstein, S. C., R. M. Steinman, and Z. A. Cohn (1977) Endocytosis. Annu. Rev. Biochem. 40: 669-722.

Staines, W. V., H. Kimura, H. C. Fibiger, and E. G. McGeer (1980) Peroxidase labelled lectin as a neuroanatomical tracer: Evaluation in a CNS pathway. Brain Res. 197: 485-490.
Steindler, D. A., and J. M. Deniau (1980) Anatomical evidence for collateral branching of substantia nigra neurons: A combined horseradish peroxidase and $\left[{ }^{3} \mathrm{H}\right]$ wheat germ agglutinin axonal transport study in the cat. Brain Res. 196: 228-236.

Sternberger, L. A., P. H. Hardy, Jr., J. J. Cuculis, and H. G. Meyer (1970) The unlabelled antibody-enzyme method of immunohistochemistry. Preparation and properties of soluble antigen-antibody complex (horseradish peroxidase-antihorseradish peroxidase) and its use in identification of spirochetes. J. Histochem. Cytochem. 18: 315-333.

Stöckel, K., M. Schwab, and H. Thoenen (1975) Comparison between the retrograde axonal transport of nerve growth factor and tetanus in motor, sensory and adrenergic neurons. Brain Res. 99: 1-16.

Stöckel, K., M. Schwab, and H. Thoenen (1977) Role of gangliosides in the uptake and retrograde axonal transport of cholera and tetanus toxin as compared to nerve growth factor and wheat germ agglutinin. Brain Res. 132: 273-285.

Zanetta, J. P., G. Roussel, M. S. Ghandour, G. Vincendon, and G. Gombos (1978) Postnatal development of rat cerebellum: Massive and transient accumulation of concanavalin- $A$ binding glycoproteins in parallel fiber axolemma. Brain Res. 142: 301-319.

Ziegler, M. G., J. A. Thomas, and D. M. Jacobowitz (1976) Retrograde axonal transport of antibody to dopamine- $\beta$-hydroxylase. Brain Res. 104: 390-395. 